IZA DP No. 9121

A Big Fish in a Small Pond: Ability Rank and Human Capital Investment

Benjamin Elsner

Ingo $\mathrm{E}$. Isphording

June 2015 


\title{
A Big Fish in a Small Pond: Ability Rank and Human Capital Investment
}

\author{
Benjamin Elsner \\ $I Z A$ \\ Ingo E. Isphording
}

IZA

Discussion Paper No. 9121

June 2015

IZA

P.O. Box 7240

53072 Bonn

Germany

Phone: +49-228-3894-0

Fax: +49-228-3894-180

E-mail: iza@iza.org

Any opinions expressed here are those of the author(s) and not those of IZA. Research published in this series may include views on policy, but the institute itself takes no institutional policy positions. The IZA research network is committed to the IZA Guiding Principles of Research Integrity.

The Institute for the Study of Labor (IZA) in Bonn is a local and virtual international research center and a place of communication between science, politics and business. IZA is an independent nonprofit organization supported by Deutsche Post Foundation. The center is associated with the University of Bonn and offers a stimulating research environment through its international network, workshops and conferences, data service, project support, research visits and doctoral program. IZA engages in (i) original and internationally competitive research in all fields of labor economics, (ii) development of policy concepts, and (iii) dissemination of research results and concepts to the interested public.

IZA Discussion Papers often represent preliminary work and are circulated to encourage discussion. Citation of such a paper should account for its provisional character. A revised version may be available directly from the author. 


\title{
ABSTRACT \\ A Big Fish in a Small Pond: Ability Rank and Human Capital Investment ${ }^{*}$
}

\begin{abstract}
We study the impact of a student's ordinal rank in a high school cohort on educational attainment several years later. To identify a causal effect, we compare multiple cohorts within the same school, exploiting idiosyncratic variation in cohort composition. We find that a student's ordinal rank significantly affects educational outcomes later in life. If two students with the same ability have a different rank in their respective cohort, the higher- ranked student is significantly more likely to finish high school, attend college, and complete a 4-year college degree. These results suggest that low-ranked students under-invest in their human capital even if they have a high ability compared to most students of the same age. Exploring potential channels, we find that students with a higher rank have higher expectations about their future career, a higher perceived intelligence, and receive more support from their teachers.
\end{abstract}

JEL Classification: $\quad$ I21, I23, J24

Keywords: human capital, ordinal rank, peer effects, educational attainment

Corresponding author:

Benjamin Elsner

Institute for the Study of Labor (IZA)

Schaumburg-Lippe-Str. 5-9

53113 Bonn

Germany

E-mail: elsner@iza.org

\footnotetext{
*We would like to thank Peter Arcidiacono, Jan Bietenbeck, Deborah Cobb-Clark, Rajeev Dehejia, Jan Feld, Chris Jepsen, Peter Kuhn, Herb Marsh, Julia Anna Matz, Milena Nikolova, Aderonke Osikominu, Daniele Paserman, Dan Rees, Ying Shi, Derek Stemple, Andreas Steinmayr, Ulf Zölitz, as well as audiences at IZA, RWI, U Mainz, IAB, Modul University, and WU Vienna for helpful comments.
} 


\section{NON-TECHNICAL SUMMARY}

Parents often believe that high-ability classmates have a positive influence on their children, and potential classmates are often a decisive factor for choosing a school. In this paper, we show that having high-ability peers in school is not beneficial for everyone. A student who is surrounded by peers that are smarter than herself has a low ordinal rank within her peer group, which may come with some disadvantages. While she may benefit from studying with smarter peers, she may experience a disadvantage, for example, because teachers give more attention to higher-ranked students, or because higher-ranked students have a higher self-confidence and higher expectations about their future career.

In this paper, we test whether a student's ordinal rank in a high-school cohort - being the best, second-best, third-best, and so on - affects success in high school, as well as decisions to go to college. We use data from Add Health, a large-scale survey in a representative sample of US high schools, which was administered to 90,000 students in the mid-1990s. In four subsequent waves, these students have been followed until 2008, allowing us to track students from age 16 to age 30, and to link the characteristics of a high-school cohort with educational outcomes many years later.

To disentangle the effect of ordinal rank from other factors that could influence educational success - for example, school choice, absolute cognitive ability, parental background, or ethnicity - we compare students who go to the same school and who have the same absolute ability, gender, parental background, etc., but who are in different cohorts. Because not every cohort is the same - some cohorts are smarter than others - a student with the same absolute level of cognitive ability has a different ordinal rank in different cohorts.

Overall, we find that a student's ordinal rank plays an important role for college choices and success in college. We find that in a cohort of 100 students a student who ranks 10 places higher than another is one percentage point more likely to go to college after high-school, and, equally, one percentage point more likely to complete a 4-year college degree. These results suggest that smart students who have a low rank because their peers are even smarter under-invest in their human capital; they choose not to go to college because of their low rank within their cohort.

We also give suggestive evidence why rank matters. We find, for example, that students of higher rank have a higher perceived intelligence, and they have higher expectations about their future career. Moreover, students of a higher rank receive more support from their teachers. 


\section{INTRODUCTION}

The characteristics of potential classmates are among the decisive factors for parents when choosing a school for their child. It is commonly believed that children learn and achieve more when surrounded by high-ability classmates. In this paper, we explore a channel that runs counter to the positive impact of high-ability peers: a student's ordinal rank in her peer group. Smart students who have a low relative ability compared to their peer group — small fish in a big pond - may erroneously conclude that they have a low absolute ability and, thus, under-invest in their human capital. Psychologists have labeled this phenomenon the big-fish-in-a-little-pond effect (Marsh, 1987).

In this paper, we test whether being a big fish in a high school cohort affects the critical transition from high school to college. Consider two students, Jack and Jim, who have the same absolute ability, but a different rank in their respective high school cohort: Jack is among the students with the lowest ability in his cohort, while Jim is among the brightest students in his cohort. In other words, Jim is a big fish in a small pond. Here we analyze whether Jim is more likely than Jack to finish high school, attend college, and complete a 4-year college degree.

To identify a causal effect, we exploit idiosyncratic changes in the cohort composition within the same school over time. We argue that, conditional on attending a given school, the cohort composition is exogenous to the student. Entering a school in a given cohort is mainly determined by a student's birth date and is beyond the influence of parents or students.

We use data from the National Longitudinal Study of Adolescent to Adult Health (AddHealth), a representative survey that tracks students in the US from middle and high school to their mid-30s, and contains rich information on cognitive skills and educational outcomes. Key to our identification strategy is that AddHealth covers multiple cohorts within the same high school, allowing us to exploit the within-school variation in cohort composition. Moreover, the survey includes an age-specific standardized ability test, which makes cognitive ability comparable within and across schools and cohorts. Based on these test scores, we compute a student's rank as the percentile in the ability distribution of her school cohort.

Our central finding is that a student's ability rank in a high school cohort has a strong impact on educational outcomes later in life. A one-decile increase in a student's rank position - the difference between the first- and the third-best student in a grade of 20 students-increases the probability of high-school completion by half a percentage point, and increases both the probabilities of college attendance and 4-year-degree completion by one percentage point. Given that cognitive ability, parental education, as well as school and cohort characteristics are held constant, these are large effects. Within a school cohort, the effect is non-linear; it is virtually zero in the lower half of the ability distribution, and strongly positive in the upper half.

While our estimation strategy rules out that the results are driven by selection into schools, the identification may be threatened by school-specific cohort characteristics that are systematically related to educational attainment. One potential confounder is average peer ability, which has been shown in many studies to improve student performance. Our baseline specification 
would not be able to fully disentangle the negative rank effect from the positive impact of average peer ability. To net out the direct influence of average cohort characteristics on educational attainment, we apply a more demanding specification that includes school-by-cohort fixed effects. This approach absorbs the mean differences across cohorts within a school and identifies the effect only through differences in the variance of the ability distribution across cohorts. The results are unchanged, suggesting that the effect of rank on educational attainment is not biased by school-specific cohort characteristics.

In theory, this result can be explained by at least four mechanisms. First, the rank may provide students with incomplete information of their own absolute ability. Students may conclude from a low relative ability that they have a low absolute ability. This misperception may distort the trade-off between the costs and benefits of education. Students may choose not to go to college if a low perceived ability translates into low expected returns to college. Second, rank can affect intrinsic factors. Students with a higher rank may be more motivated and self-confident and, hence, put more effort into their studies, which then translates into a higher chance of going to college. Third, a student's environment may be responsive to a student's rank. Teachers, family, and friends may offer more support to high-ranked students, leading to better grades and a higher chance of going to college. Finally, the result could be explained by selective college admission policies. Colleges often observe a student's GPA rank within a cohort, which is correlated with our rank measure. If admissions officers give priority to students with a higher rank regardless of the school quality, or if colleges automatically admit the top $10 \%$ of a school cohort, then this can explain the effect.

While we are not able to fully disentangle these mechanisms, we exploit the rich survey information in AddHealth to provide suggestive evidence that some channels are more important than others. We find strong evidence for the expected earnings channel. Applying the same empirical strategy as before, we find that a higher rank has an equally large effect on various measures of career expectations at the age of 16 as it has on the actual outcomes 14 years later. Moreover, we find that students with a higher rank are more optimistic, have a higher perceived intelligence, and put more effort into their studies, while we find no relationship between rank and various measures of well-being, happiness, and depression. In terms of support from their environment, students with a higher rank report a higher perceived support from their teachers, while the rank is not related to support from parents and friends. Finally, while we have no information on the type of college to which students are admitted, we can exclude that the effect is purely driven by selective college admissions. When we run our baseline model and additionally control for GPA, the effect of the ability rank on educational attainment remains large and statistically significant, indicating that GPA-based college admissions explain only a fraction of the effect.

With this paper, we contribute to three strands of the literature. First, this paper extends the literature on ordinal rank and education outcomes. A large literature in psychology focuses on a student's academic self-concept, showing that students with a higher ordinal rank have a higher perceived ability in various school subjects (Marsh, 1987; Marsh et al., 2007). The first 
rigorous causal estimate of ordinal rank on educational performance is provided by Murphy \& Weinhardt (2014), who use administrative school data from the UK, and find a strong positive impact of ordinal rank in primary school on test scores in secondary school. Our paper uses a very similar research design, but departs from their study in two important dimensions. First, our data cover a longer time span, allowing us to estimate long-run effects of ordinal rank. Second, in addition to performance, we show that a student's ordinal rank affects actual choices in the transition from high school to college, which are crucial for future careers.

More broadly, this paper speaks to the literature on peer effects in education. So far, there is no consensus if and to what extent peers matter for student performance. While earlier studies have found that higher peer quality has a positive impact on test scores and affects later education choices, more recent studies show that peer effects are non-linear and can even be negative for some students. ${ }^{1}$ The ordinal rank effect found in this paper provides one explanation for these ambiguous effects. The positive effect of having better peers can be offset by having a lower ordinal rank.

This paper also contributes to the literature on imperfect information and educational choices. The evidence shows that students have imperfect knowledge of their own ability (Stinebrickner \& Stinebrickner, 2012, 2014; Zafar, 2011; Bobba \& Frisancho, 2014) and are uncertain about their returns to education (Jensen, 2010; Attanasio \& Kaufmann, 2015; Wiswall \& Zafar, 2015). Our results suggest that the ordinal rank is one of the reasons why students have incorrect beliefs about their absolute ability. In their education decisions, students seem to place substantial weight on their relative ability, which leads to suboptimal education choices.

\section{Data and Descriptive Statistics}

\subsection{The AdDHeAlth DATA}

Our data is the restricted-use version of AddHealth, a representative longitudinal dataset of US middle and high schools. Four features of AddHealth are key to our study: first, it covers multiple cohorts within the same school. This is critical for identification, because we can compare students in adjacent cohorts within the same school, and exclude selection into schools as a main confounding factor. Second, within every school cohort, we observe a representative sample of students from which we can construct the ability ranking. Third, the longitudinal set-up allows us to link the ordinal rank in high school to outcomes 14 years later and to observe the critical transition from high school to tertiary education. Finally, the survey includes a standardized test that provides us with an objective measure of cognitive ability. Unlike in most

1 The evidence for positive peer effects on student performance ranges from primary schools (Hanushek et al., 2003; Ammermueller \& Pischke, 2009) to high schools (Calvó-Armengol et al., 2009; Imberman et al., 2012) to college (Sacerdote, 2001; Zimmerman, 2003; Carrell et al., 2009; De Giorgi \& Pellizzari, 2014; Booij et al., 2015). Bifulco et al. (2011) and Patacchini et al. (2012) show that better peers also increase the likelihood of going to college. Studies that find a non-linear effect or zero effect are Lavy et al. (2012), Koppensteiner (2012), Carrell et al. (2013), Burke \& Sass (2013), Pop-Eleches \& Urquiola (2013), Abdulkadiroglu et al. (2014), Feld \& Zölitz (2014), Tincani (2015) and Tatsi (2015). 
other datasets, we can directly measure cognitive ability without having to resort to grades or other self-reported measures as proxies.

To date, four waves of AddHealth are available. The first wave was administered in 1994/1995, when students were between 13 and 18 years old. Follow-ups were run in 1996, in 2000/2001 when most students had left high school, and in 2008/2009, when most had entered the labor market. In the first wave, a representative sample was drawn among all public and private high schools in the US. Within each school, students from grades 7-12 were sampled. In total, we observe up to six cohorts within a school. All cohorts were interviewed at the same time; therefore, we only observe each cohort in one grade, i.e., we observe the 1994 entry cohort in grade 7, the 1993 entry cohort in grade 8, the 1992 entry cohort in grade 9, etc. Given that we observe each cohort only in one grade, we will use cohort and grade interchangably. ${ }^{2}$

The first wave consisted of two questionnaires: a basic In-school questionnaire, which was administered to all students in the surveyed schools, and a more comprehensive In-home questionnaire, which was answered by a randomly drawn subsample of students within each school. For the In-home sample, 17 boys and 17 girls were randomly drawn from each grade within each school. Additional students were drawn to oversample groups with certain characteristics: twins, students with disabilities, Blacks from well-educated families, as well as students of Chinese, Cuban, and Puerto Rican origin. ${ }^{3}$

Our main sample is the In-home sample of the first wave, which we complement with information on the educational attainment from the fourth wave. We drop from the sample all schools with 20 observations or less (109 obs.) and all grades with 5 students or less (304 obs.). Moreover, due to attrition, we drop all students for whom we do not observe the educational attainment (finished high school, attended any type of college, completed college) or other observable characteristics in wave IV (4,711 obs.). In total, our sample consists of 13,645 students in 130 schools and 432 grades.

\subsection{OUtcome VARIABles: EducAtional ATtainment}

We consider three outcome variables that measure different degrees of educational attainment: completed high school, attended college, completed a 4-year college degree. These measures are taken from wave IV of AddHealth, where respondents were asked about their highest educational attainment. The categories attended college and completed a 4-year college degree are nested; completed a 4-year college degree only includes students who completed at least a Bachelor's degree, while attended college is broader and also includes students who attended college but finished with less than a Bachelor's, or did not finish at all.

Table 1 summarizes the outcome variables for various groups. Among all students, 93\%

$2 \quad$ In schools that integrate high- and middle schools and that offer grades 7 to 12, all grades were sampled. In high schools that only offer grades $9-12$, grades 7 and 8 were sampled from a random middle school (so-called feeder school) that was drawn from all surrounding middle schools that send students to the given high school. For further information on the study design and the sampling, see Harris (2009) and Harris et al. (2009).

3 In 16 so-called saturated schools, all students that were present on the day of the survey were included. 
completed high school, while $67 \%$ attended college. Around half of those who attended college finished at least with a Bachelor's degree. ${ }^{4}$

Across subgroups, the educational attainment differs considerably. In all three measures, women have a higher educational attainment than men. The data also reveal a high correlation between the educational attainment of the parents and their children. Children of collegeeducated parents are four times as likely to complete a college degree and ten times less likely to drop out of high school than children whose parents were high school dropouts. There is less variation in the educational attainment across ethnic groups. Hispanics and Blacks have lower educational attainment than Whites, but the raw differences are less than 10 percentage points. An exception are students of Asian descent, whose educational attainment is considerably higher than in all other groups.

Finally, we consider schools with different average ability and heterogeneity. Unsurprisingly, students from schools in the top half have a higher educational attainment. We also check if more heterogeneous schools are more or less conducive to educational success. If schools are homogeneous with respect to ability, for example, because of tracking or because of neighborhood segregation, one would expect homogeneous schools to have different outcomes than heterogeneous schools. The raw data, however, do not support this conjecture.

\subsection{RANKING STUDENTS}

The regressor of interest is a student's ordinal rank in the ability distribution of a high-school cohort. We are interested in estimating a causal effect of rank on educational outcomes, which we identify by comparing students within the same school and with the same level of absolute ability who differ in their ordinal rank because they are in different cohorts. This identification strategy requires a standardized ability test that makes students comparable across cohorts within the same school. To obtain a standardized measure of cognitive ability, we use the scores of a standardized Peabody Picture Vocabulary Test, of which a shortened version was included in the survey. The test works as follows: participants are asked to allocate words spoken aloud by the interviewer to a set of four pictures. The test proceeds through multiple rounds with increasing difficulty. The test is age-specific, with test scores being standardized to mean 100 and standard deviation 15 within an age group. The scores are computed automatically, without being made available to the interviewer or the respondent. ${ }^{5}$ Though measuring very basic cognitive skills, the Peabody test has been shown to have a high re-test reliability and correlates highly with other intelligence tests for adolescents (Dunn \& Dunn, 2007).

Based on the Peabody score, we compute a student's ordinal rank as her percentile in the ability distribution of her school cohort. If a grade has 100 students, the student with the highest

\footnotetext{
4 These numbers confirm the representativeness of the survey, as they are very close to the means in the American Community Survey (ACS): 91\% have completed high school, 64\% attended any type of college, and $31 \%$ completed a 4-year degree. These calculations are based on the 2007-2011 Public Use File of individuals born between 1976 and 1982 (US natives and immigrants who arrived before 1995).

5 Further information on the Addhealth Picture Vocabulary Test is available in the AddHealth documentation at http://www.cpc.unc.edu/projects/addhealth/data/guides.
} 
Table 1: Educational attainment by group

\begin{tabular}{|c|c|c|c|c|c|c|c|}
\hline \multirow[t]{2}{*}{ Group } & \multicolumn{2}{|c|}{$\begin{array}{l}\text { completed } \\
\text { High school }\end{array}$} & \multicolumn{2}{|c|}{$\begin{array}{l}\text { attended } \\
\text { College }\end{array}$} & \multicolumn{2}{|c|}{$\begin{array}{c}\text { completed } \\
\text { 4-year degree }\end{array}$} & \multirow[t]{2}{*}{$N$} \\
\hline & mean & (SD) & mean & (SD) & mean & (SD) & \\
\hline All & 0.93 & $(0.26)$ & 0.67 & $(0.47)$ & 0.33 & $(0.47)$ & 13645 \\
\hline Male & 0.91 & $(0.28)$ & 0.63 & $(0.48)$ & 0.29 & $(0.45)$ & 6330 \\
\hline Female & 0.94 & $(0.23)$ & 0.71 & $(0.45)$ & 0.37 & $(0.48)$ & 7315 \\
\hline \multicolumn{8}{|l|}{ Parental background: } \\
\hline Less than high-school & 0.81 & $(0.39)$ & 0.45 & $(0.50)$ & 0.13 & $(0.33)$ & 1957 \\
\hline High school & 0.91 & $(0.29)$ & 0.55 & $(0.50)$ & 0.19 & $(0.39)$ & 3399 \\
\hline Some college & 0.94 & $(0.23)$ & 0.68 & $(0.47)$ & 0.28 & $(0.45)$ & 3423 \\
\hline College & 0.98 & $(0.14)$ & 0.85 & $(0.36)$ & 0.54 & $(0.50)$ & 4866 \\
\hline \multicolumn{8}{|l|}{ Race/Ethnicity: } \\
\hline White & 0.94 & $(0.25)$ & 0.69 & $(0.46)$ & 0.36 & $(0.48)$ & 7733 \\
\hline Asian & 0.98 & $(0.15)$ & 0.78 & $(0.42)$ & 0.49 & $(0.50)$ & 882 \\
\hline Hispanic & 0.90 & $(0.30)$ & 0.61 & $(0.49)$ & 0.23 & $(0.42)$ & 1961 \\
\hline Black & 0.91 & $(0.28)$ & 0.65 & $(0.48)$ & 0.28 & $(0.45)$ & 3069 \\
\hline \multicolumn{8}{|l|}{ Average school ability: } \\
\hline High average ability (above median) & 0.96 & $(0.20)$ & 0.74 & $(0.44)$ & 0.42 & $(0.49)$ & 6730 \\
\hline Low average ability (below median) & 0.90 & $(0.30)$ & 0.61 & $(0.49)$ & 0.24 & $(0.43)$ & 6915 \\
\hline \multicolumn{8}{|c|}{ School heterogeneity (within-school SD in ability) } \\
\hline High heterogeneity(above median) & 0.92 & $(0.27)$ & 0.67 & $(0.47)$ & 0.32 & $(0.47)$ & 7410 \\
\hline Low heterogeneity (below median) & 0.93 & $(0.25)$ & 0.68 & $(0.47)$ & 0.34 & $(0.47)$ & 6235 \\
\hline
\end{tabular}

Notes: This table displays the share of people who completed high school, the share of people who enrolled in college, and the share of people who finished a 4-year college degree. Standard deviations are reported in parentheses. Parental background refers to the highest level of education and the highest occupational status among both parents. Average school ability is the average ability of the entire school, and above/below median refers to the school distribution, i.e. students in the "above median" group attend schools with an above-median ability-level. The school heterogeneity is measured by the within-school standard deviation of ability.

ability is assigned rank 100, and the student with the lowest ability is assigned rank 1. Students with the same test score are assigned an equal rank. For the analysis, the absolute rank measure is problematic, because it is not comparable across grades with different sizes. Simply put, being the second best in a grade of 100 students means more than being the second best in a grade of 10 students. The percentile rank is standardized to cohort size, assigning value 1 to the student with the highest rank in a grade, and 0 to the lowest:

$$
\text { percentile rank }=\frac{\text { absolute rank }-1}{\text { nr of students in grade }-1} .
$$

The Peabody score is our preferred measure for ranking students according to their ability, because the scores are comparable across grades and schools. Another suitable measure would be the grade point average (GPA). Rather than measuring relative ability, a ranking based on GPA would measure relative performance. Performance, in turn, is a function of many factors besides cognitive ability, such as effort, ambition, or the choice of courses. Moreover, 
within many schools, GPAs are not comparable across cohorts because students are graded on a curve - the same grade distribution is applied within every subject—or grading may depend on the individual teacher.

But are students aware of their ability rank, that is, do students know their own ability compared to the ability of others in the same cohort? While we cannot directly infer students' knowledge of their exact ranks from the survey, we have two pieces of evidence that suggest that students have an idea about their relative ability in their cohort. First, students with the same absolute ability but a higher ordinal rank have a higher perceived intelligence. When asked if they believe that they are more intelligent than the average, students of a higher rank are significantly more likely to agree than students of lower rank, after controlling for own ability, personal characteristics, and only comparing students within schools across cohorts. A second piece of evidence is that students of higher rank have higher expectations about their educational career. For example, they are more likely to expect to finish a college degree later in life. This would hardly be the case if students had no idea about their relative ability.

\subsection{SUMMARY STATISTICS}

Table 2 displays the summary statistics. Panel A summarizes the ability measures and other individual characteristics. The two columns on the right display the means for students in the bottom and top half of the within-grade ability distribution. At first glance, women and Blacks are over-represented among students in the bottom half of a grade, while there is no large difference with respect to average age, and the share of Hispanics, students of Asian descent, or students with a migration background. A strong correlation appears between ability and parental education. Children of highly educated parents are more likely to have a higher rank within their grade.

Panel B summarizes the average school and grade characteristics. Schools differ considerably in terms of average ability and heterogeneity. Students in the lowest-ability school scored, on average, 79 on the standardized test, which is three between-school standard deviations below the mean; the highest-ability school scored 116, or 2.5 between-school standard deviations above the mean. To measure heterogeneity in ability, we take the within-school standard deviation of the ability distribution. The within-school standard deviation varies between 9.2 and 20.5, and is on average twice as large as the between-school standard deviation, which is 6.5.

Depending on the school, the grade size varies greatly; in the population, it ranges from 5 in the smallest grade to 645 in the largest. More relevant for our study is the actual withingrade sample size. The average grade has 40 students in the sample, which is more than the 34 students drawn at random due to oversampling of minorities and the inclusion of saturated schools. On average, $22 \%$ of a grade have been sampled. 
Table 2: Summary Statistics of the main variables

\begin{tabular}{|c|c|c|c|c|c|}
\hline Variable & $N$ & $\begin{array}{c}\text { All } \\
\text { Mean }\end{array}$ & $S D$ & $\begin{array}{r}\text { bottom } 50 \% \\
\text { Mean } \\
\end{array}$ & $\begin{array}{r}\text { top } 50 \% \\
\text { Mean } \\
\end{array}$ \\
\hline \multicolumn{6}{|l|}{ A. Individual characteristics } \\
\hline \multicolumn{6}{|l|}{ Ability } \\
\hline Cognitive ability & 13645 & 101.14 & 14.24 & 91.18 & 110.84 \\
\hline Ability rank & 13645 & 0.50 & 0.29 & 0.24 & 0.75 \\
\hline \multicolumn{6}{|l|}{ Personal characteristics } \\
\hline Age & 13645 & 16.13 & 1.68 & 16.25 & 16.01 \\
\hline Female & 13645 & 0.54 & 0.50 & 0.57 & 0.50 \\
\hline Ever repeated a grade & 13645 & 0.20 & 0.40 & 0.28 & 0.13 \\
\hline Migration background (1st \& 2nd gen.) & 13645 & 0.15 & 0.36 & 0.16 & 0.14 \\
\hline Asian & 13645 & 0.06 & 0.25 & 0.06 & 0.07 \\
\hline Black & 13645 & 0.22 & 0.42 & 0.27 & 0.19 \\
\hline Hispanic ancestry & 13645 & 0.14 & 0.35 & 0.16 & 0.13 \\
\hline \multicolumn{6}{|l|}{ Highest parental education } \\
\hline Less than high-school & 13645 & 0.14 & 0.35 & 0.19 & 0.10 \\
\hline High-school & 13645 & 0.25 & 0.43 & 0.29 & 0.21 \\
\hline Some college & 13645 & 0.25 & 0.43 & 0.24 & 0.26 \\
\hline College & 13645 & 0.36 & 0.48 & 0.29 & 0.42 \\
\hline \multicolumn{6}{|l|}{ B. School and grade characteristics } \\
\hline School characteristics & $N$ & Mean & $S D$ & Min & $\operatorname{Max}$ \\
\hline Small (< 401 students $)$ & 130 & 0.22 & 0.42 & & \\
\hline Medium (401-1000 students) & 130 & 0.47 & 0.50 & & \\
\hline Large $(>1000$ students $)$ & 130 & 0.31 & 0.46 & & \\
\hline Average class size & 128 & 25.86 & 5.18 & 10.00 & 39.00 \\
\hline Mean ability & 130 & 100.31 & 6.46 & 79.19 & 115.80 \\
\hline SD ability & 130 & 12.89 & 2.29 & 9.24 & 20.48 \\
\hline \multicolumn{6}{|l|}{ Grade characteristics } \\
\hline Grade size (population) & 432 & 184.27 & 131.54 & 5 & 645 \\
\hline Nr students in sample & 432 & 40.63 & 45.27 & 6 & 545 \\
\hline
\end{tabular}

Notes: Panel A displays the means and standard deviations of the main variables for the whole sample, as well as the means for the students above and below the median ability of their school grade. Besides the share of students of Asian descent, all differences are statistically significant at the 1\%-level. Panel B displays the average school and grade characteristics. The school characteristics have been reported by the school administrator in a separate survey. In two cases, the information on the average class size was missing.

\section{IDEntification AND Estimation Strategy}

Our aim is to estimate a causal effect of a student's ability rank on educational attainment later in life. In this section, we first describe the identifying variation. We then lay out the econometric model, and discuss the identifying assumptions, as well as potential threats to identification. 


\subsection{IDENTIFYING VARIATION}

To estimate a causal effect, we exploit idiosyncratic variation in cohort composition within the same school over time. The idea is that students with the same level of absolute abilty have a different rank if they are in cohorts with different ability distributions. The variation in cohort composition can be due to differences in mean ability - some cohorts are on average brighter than others. It can also be due to differences in the dispersion of ability within a cohort - in some cohorts the ability is more evenly distributed than in others. Figure 1, panel (A) illustrates the identifying variation based on differences in mean ability for two entry cohorts in the same school, each consisting of 4 students. The 1994 entry cohort has a lower average ability, such that a student with cognitive ability abil would have the second rank. If she entered the school in 1995, when the entry cohort was stronger, she would only have the third rank, despite having the same cognitive ability.

A

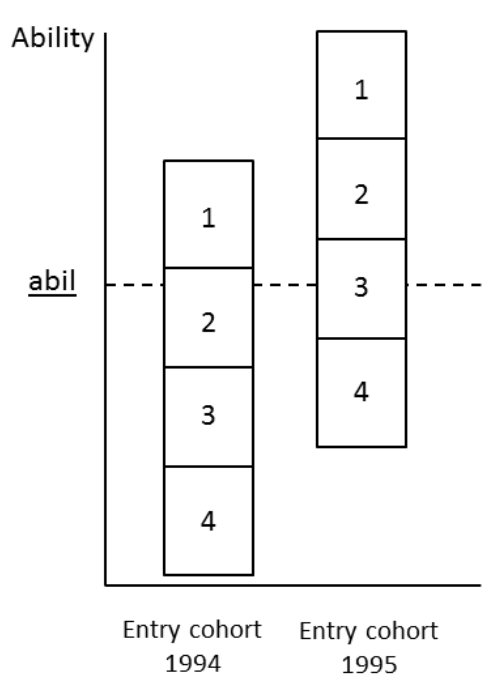

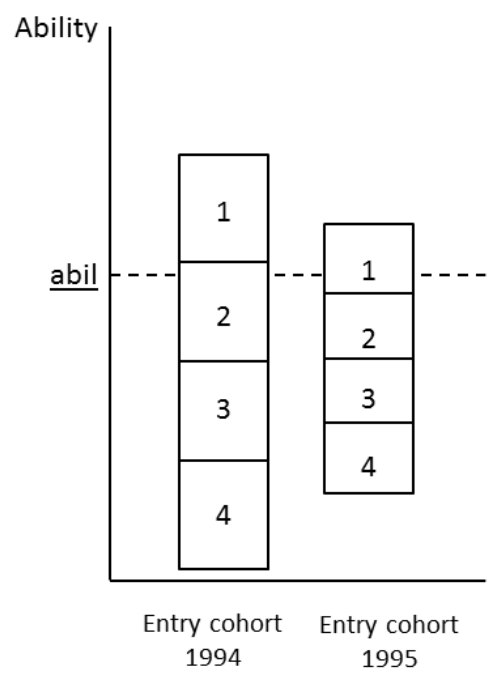

Figure 1: Identifying variation: a student with ability=abil has rank 1 in the entry cohort in 1994 but rank 2 in 1995. Identification based on (a) differences in means or (b) differences in shape of ability distribution

By only using variation within schools, we can rule out that the variation in cohort composition is driven by systematic self-selection of students into schools. ${ }^{6}$ But within a school, where could the differences in the ability distribution across cohorts come from? As explained

$6 \quad$ In fact, there is evidence that parents strategically choose schools with their kids' rank in mind. Cullen et al. (2013) show that after automatic admission to the flagship state universities in Texas was granted to the top $10 \%$ of a school, parents deliberately sent their kids to lower-ability schools in order to give them a higher chance of being in the top $10 \%$. 
by Hoxby (2000a), one source of variation is the timing of births in combination with a cutoff date between school years. If in some years more children are born before the age cut-off than in others, this leads to fluctuations in the cohort sizes within the same school. Along the same lines, the characteristics of parents may fluctuate from year to year. In some years, the share of children born to highly educated parents is higher than in others, the share of Black or Hispanic children is higher than in others, or in some years more children with a higher innate ability are born than in others. Due to the law of large numbers, such fluctuations may not be pronounced in the entire US or in one state, but they are more pronounced within a school district, where the law of large numbers does not necessarily hold. Our identification relies on this idiosyncratic variation in the population.

We will employ two identification strategies. Both exploit changes in the within-school cohort composition over time, but rely on different sources of variation. The first strategy follows Hoxby (2000b) and Bifulco et al. (2011), among others, and compares the outcomes of students in adjacent cohorts within the same school, as illustrated in Panel A) of Figure 1. We choose the first strategy for our baseline model because of its intuitive appeal. It is straightforward to think of an underlying experiment in which we compare the outcomes of students with the same cognitive ability, age, parental background, etc, and attribute the difference in their educational attainment to differences in ordinal rank. The drawback of this identification strategy is that it does not fully account for school-cohort-specific confounders, for example, average peer quality. The second identification strategy is less intuitive at first sight, but it ultimately rules out these confounders. We follow Murphy \& Weinhardt (2014) and employ a specification with schoolspecific grade fixed effects. This strategy eliminates differences in grade means of observable and unobservable characteristics; identification comes from differences in the dispersion of the ability distribution across grades within a school. It absorbs all average differences between cohorts within a school, as well as school-specific time trends. Figure 1, panel (B) illustrates this alternative identifying variation. In this case, the entry cohorts of 1994 and 1995 only differ by the spread of the distribution. Still, students with the same cognitive ability $\underline{a b i l}$ will end up with different ranks.

\subsection{EstimATING EQUATION}

The following regression setup relates the educational attainment in wave IV of the survey (in 2008) to a student's ordinal rank in high school measured in wave I (in 1994/1995):

$$
\begin{aligned}
& \text { Educ. attainment }{ }_{i j k}=\gamma \text { ordinal } \operatorname{rank}_{i j k}+g\left(\operatorname{cog} \cdot \text { ability }_{i j k}\right)+\boldsymbol{X}_{\boldsymbol{i j k}}^{\prime} \boldsymbol{\beta} \\
& + \text { School } \mathrm{FE}_{j}+\text { Grade } \mathrm{FE}_{k}+\varepsilon_{i j k} \text {. }
\end{aligned}
$$

We consider the three outcome variables in separate regressions. The outcome variable of person $i$ who attended high school $j$, and grade $k$ is a dummy variable that takes value one if a person has achieved a certain educational attainment — completed high school, attended any 
college, or completed a 4-year degree - and zero otherwise. The coefficient of interest is $\gamma$, which measures the impact of a marginal increase in the percentile rank of a student within a high school cohort on educational attainment.

Given that a person's ordinal rank is determined by her cognitive ability, the ordinal rank could be seen as a mere proxy for cognitive ability, in which case $\gamma$ could be interpreted as the marginal effect of cognitive ability and not of ordinal rank. To ensure that $\gamma$ exclusively measures the marginal effect of ordinal rank, we control for a person's cognitive ability with a fourth-order polynomial $g\left(\operatorname{cog}\right.$. ability $\left.{ }_{i j k}\right)$, which captures the potential non-linear relationship between ability and educational attainment.

As shown in Table 1, the outcome variables differ considerably between demographic groups. For example, men have lower educational attainment than women, Blacks have lower educational attainment than Whites, and children of highly educated parents have a higher educational attainment. The vector of individual control variables $\boldsymbol{X}_{\boldsymbol{i j k}}$ accounts for these (pre-treatment) differences and ensures that in our regression we compare students with the same observable characteristics. The controls include age in months, a dummy for gender, dummies for race/ethnicity (Asian, Black, Hispanic), a dummy for migration background (1 if a person is a first- or a secondgeneration migrant), dummies for the highest level of education of both parents (less than high school, high school, some college, college degree), and dummies for the highest occupational status of both parents (not working, blue collar, white collar low-skilled, white collar high-skilled). Finally, we include a dummy that equals one if a student has ever repeated a grade up until wave I of the survey. As shown in Table 2, repeaters are concentrated in the lower half of the ability distribution of their grade. If they also have lower educational attainment, not controlling for repeaters would lead to an upward-bias in the estimate of $\gamma$.

The inclusion of separate school and grade fixed effects restricts the variance to withinschools and across-grades. The school fixed effects remove the mean differences between schools in educational attainment, cognitive ability, as well as the demographic composition of schools. The grade fixed effects remove the mean differences in all variables between the six grade levels in our sample.

Finally, $\varepsilon_{i j k}$ is an error term that captures all unobservable factors that affect educational attainment. Because the rank is computed at the school-grade-level, the outcomes of all students within a school grade could be systematically correlated. To account for this, we cluster the standard errors at the school $\times$ grade-level. ${ }^{7}$

Within a given school, the identification of a causal effect rests on the assumption that being in a certain cohort is as good as random. This assumption only holds if at least two conditions are fulfilled:

1. Conditional on having chosen a specific school, neither parents nor students can manipulate the student's cohort.

$7 \quad$ We also compute heteroskedasticity-robust standard errors, which would take into account the heteroskedastic errors that are inherent in linear probability models. In most cases, the robust standard errors are minimally smaller than the clustered standard errors reported. 
2. Within a school, there is no systematic correlation between average cohort characteristics and educational attainment.

Violations to any of these conditions could introduce a systematic bias into the estimate of $\gamma$, as the ordinal rank would be correlated with the error term, $\operatorname{cov}\left(\right.$ ordinal $\left.\operatorname{rank}_{i j k}, \varepsilon_{i j k}\right) \neq$ 0 . Potential violations to the first condition could be due to strategic delay of school entry (redshirting) or grade repetition. Examples for violations of the second condition are changes in the cohort quality within a school, or a direct effect of the average peer quality on outcomes. For the baseline analysis to follow, we maintain the assumption that both conditions hold. In robustness checks, we will address a large number of confounding factors, and also discuss measurement error and selective attrition as potential sources of bias.

\section{RESUlts}

In this section, we present the estimation results. We begin by exploring the unconditional relationship between rank and three measures of educational attainment; we then gradually introduce fixed effects and control variables into the model. We further explore whether the effect differs between school types and whether it is non-linear within a cohort. While the baseline model rules out some obvious confounders, the results could still be biased due to omitted factors, measurement error, or attrition. In a series of robustness checks, we show that that these biases do not lead to dramatic changes in the results. Finally, we explore potential channels through which a student's rank affects educational attainment.

\subsection{BASELINE RESUlTS: ORDINAL RANK AND EDUCATIONAL ATTAINMENT}

Table 3 displays the basic results for the impact of a student's ordinal rank on educational attainment. Each coefficient is the result of a separate regressions of each of the three outcome variables - dummies for having completed high school, having attended college, and having completed college - on the ordinal rank of a student in her high school cohort. We begin in Column (1) with the unconditional relationship, and gradually introduce fixed effects and controls.

The unconditional relationship in Column (1) confirms that a higher within-grade rank is associated with higher educational attainment. An increase in the percentile rank by one decile, that is, the difference between the second- and the third-best student in a grade of ten students, or the difference between the second- and the fourth-best in a grade of 20, is associated with an increase in high school completion rates by 1.3 percentage points, which is $19 \%$ of the overall high school dropout rate $(7 \%)$. The association with attending college and completing college is even larger. A one-decile increase in the relative ability rank predicts an increase in the likelihood of going to college by 3.9 percentage points, which is $5 \%$ of the mean rate of college attendance, and an increase in the likelihood of completing college by 3.6 percentage points, which is more than $10 \%$ of the college completion rate in the sample. 
Table 3: OLS regression results: the importance of rank position

\begin{tabular}{lcccccc}
\hline \hline & $(1)$ & $(2)$ & $(3)$ & $(4)$ & $(5)$ & $(6)$ \\
\hline Dependent variable & & & & & & \\
Completed high school & $0.133^{* * *}$ & $-0.053^{* * *}$ & -0.002 & $0.054^{* *}$ & 0.034 & 0.048 \\
& $(0.009)$ & $(0.018)$ & $(0.024)$ & $(0.026)$ & $(0.025)$ & $(0.031)$ \\
Attended College & $0.386^{* * *}$ & $-0.106^{* * *}$ & $0.091^{* *}$ & $0.139^{* * *}$ & $0.103^{* * *}$ & $0.112^{* *}$ \\
& $(0.014)$ & $(0.039)$ & $(0.039)$ & $(0.041)$ & $(0.038)$ & $(0.046)$ \\
Completed 4-year degree & $0.364^{* * *}$ & $-0.266^{* * *}$ & $0.073^{*}$ & $0.121^{* * *}$ & $0.101^{* *}$ & $0.082^{*}$ \\
& $(0.013)$ & $(0.044)$ & $(0.042)$ & $(0.042)$ & $(0.040)$ & $(0.048)$ \\
& & & & & & \\
Controls: & & & & & & \\
Individual ability (quartic) & No & Yes & Yes & Yes & Yes & Yes \\
School FE & No & No & Yes & Yes & Yes & No \\
Grade FE & No & No & No & Yes & Yes & No \\
Individual controls & No & No & No & No & Yes & Yes \\
School $\times$ Grade fixed effects & No & No & No & No & No & Yes \\
Goodness of fit: & & & & & & \\
$\mathrm{R}^{2}$ Completed high school & 0.02 & 0.04 & 0.08 & 0.09 & 0.15 & 0.17 \\
$\mathrm{R}^{2}$ Attended College & 0.06 & 0.10 & 0.15 & 0.15 & 0.23 & 0.25 \\
$\mathrm{R}^{2}$ Completed College & 0.05 & 0.12 & 0.18 & 0.18 & 0.26 & 0.28 \\
\hline
\end{tabular}

Note: This table displays the results of separate OLS regressions of the dependent variables completed high school, attended college, and completed college on the percentile rank. From left to right, more controls and fixed effects are being introduced. Standard errors, clustered at the school-grade level, are displayed in parentheses, with significance levels $* \mathrm{p}<0.10,{ }^{* *} \mathrm{p}<0.05,{ }^{* * *} \mathrm{p}<0.01$.

While pointing to a strong association, the information we obtain from Column (1) is limited, because the ability rank is based on the score on the ability test, and is merely a proxy for ability due to the strong positive correlation between rank and ability. In Column (2) we control for a fourth-order polynomial in individual ability, in which case the sign of the marginal effect of ordinal rank gets reversed. Taken at face value, the results would suggest that the ordinal rank negatively affects educational attainment. While this result may seem surprising, it merely reflects a mechanical correlation between rank and school quality due to selection into schools. At a given level of ability, a student in a school with a low average ability has a higher rank than in a school with a high ability, but students in better schools have a higher educational attainment.

In Column (3) we control for unobserved heterogeneity across schools by introducing school fixed effects. Identification now only comes from within the schools. Compared to the model without fixed effects, the $R^{2}$ is considerably higher, confirming the importance of unobserved heterogeneity across schools. The coefficient for high school completion suggests that completing high school is not influenced by ordinal rank, while there is a positive association between ordinal rank and college attendance and completion.

Column (4) makes a leap towards a causal effect. While in Column (3) we estimated an average effect across all students within a school, in Column (4) we compare students with the same ability across different cohorts within the same school. We introduce grade fixed effects, 
which absorb the mean difference between different cohorts across the sample. If students who were in 7th grade in 1994 were, on average, different from those in 8th grade, this difference is accounted for in this specification. Compared to Column (3), the effects are larger and more precisely estimated. For all three outcome variables, these effects are substantial. An increase in the within-grade rank by one decile increases the likelihood of completing high school by half a percentage point, and increases college attendance and completion by 1.4 and 1.2 percentage points ( $2 \%$ and $3.6 \%$ of the mean), respectively.

In Column (5) we introduce individual control variables to take into account the differences in observable characteristics, and their potential effect on the outcome. There are two reasons for including control variables. First, as shown in Table 1, the outcome variables differ significantly across ethnic and parental backgrounds. Second, as indicated by the increased $R^{2}$ in Column (5), the control variables have additional explanatory power and ensure a better model fit. The inclusion of individual controls, however, has no statistically significant impact on the point estimates, which lends further credibility to our claim that cross-cohort variation in the ability distribution within the same school is quasi-random. The point estimates in Column (5) are slightly smaller than in Column (4), but the difference is not statistically significant.

Finally, we address the concern that the average grade characteristics, for example, average peer ability, bias the estimates. In Column (6) we include school $\times$ grade fixed effects, taking into account school-specific mean differences across grades. The only variation exploited by this specification is in the variance of the ability distribution within schools across grades. Some cohorts have a more dispersed ability distribution than others, such that a given level of ability leads to a different rank when the variances are different but the mean is the same. It is reassuring that the results from this demanding specification are similar to those in the estimation with separate sets of fixed effects in Column (5). The differences between the coefficients in Columns (5) and (6) are not statistically significant. Moreover, the results in Column (6) indicate that the variation in rank is mainly driven by the differences in variance, rather than differences in the mean ability.

In sum, these results clearly show that a student's rank matters for educational choices and outcomes. We find large and statistically significant differences in high-school completion rates, college attendance, and college completion of students who go to the same school but have a different rank in the ability distribution of their grade.

\subsection{HetERogeneous EFFECTS}

While the regression results in Table 3 show a positive impact of high school rank position on educational attainment, the strength of this impact differs along the ranking and across school types. The first three rows in Figure 2 displays the results for different school types, which we obtained by re-estimating Equation 3 on split samples. The three classifications are given in the survey and are the only available measure of school size. As shown in the first row, the effects differ considerably by school size. For college attendance and completion, the effects are mainly driven by large and medium-sized schools, while the effect for high-school completion is larger 

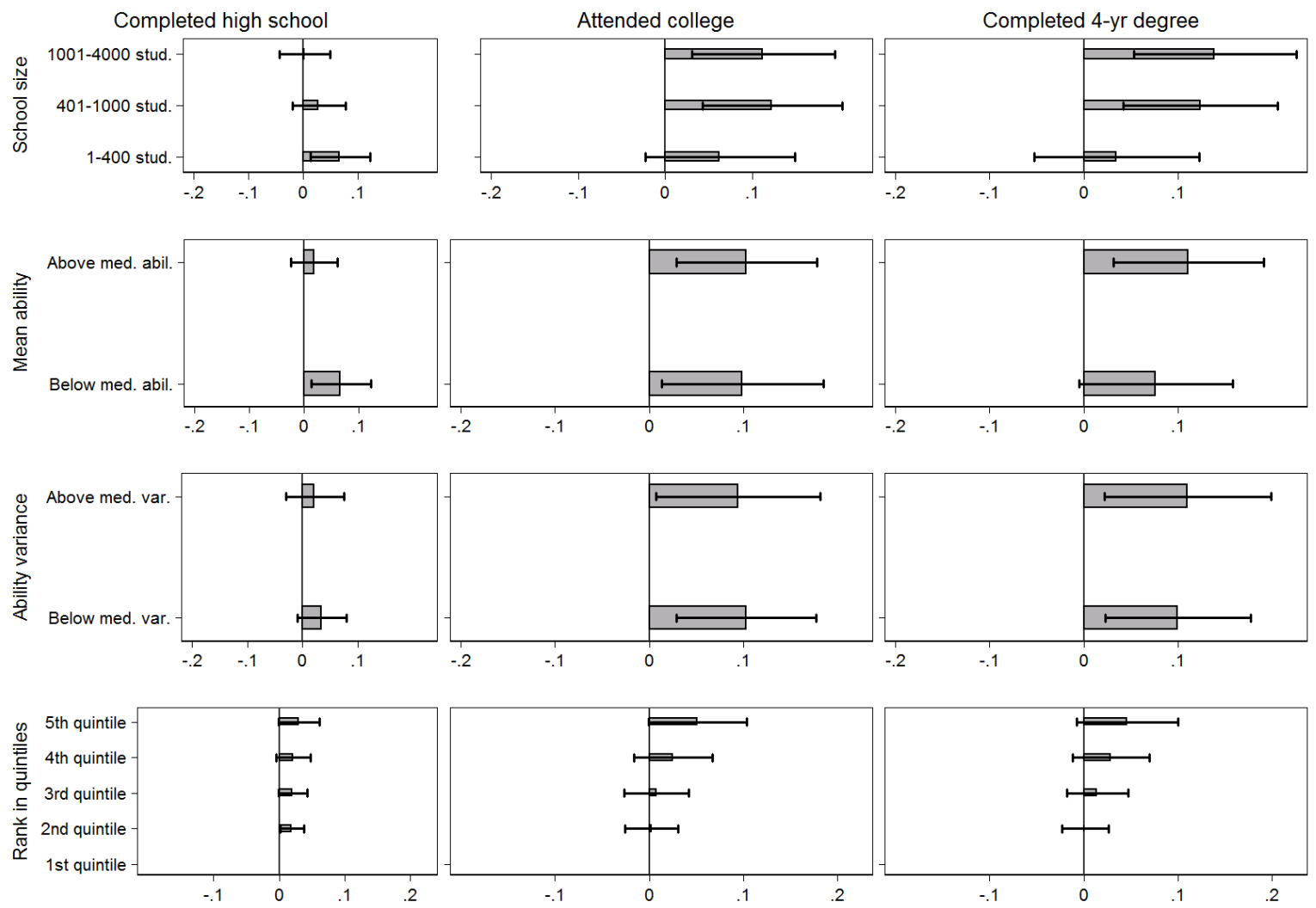

Figure 2: OLS results: heterogeneous effects across school types and grades

Note: The first three rows display the marginal effects of rank on educational attainment for different school types. The bottom panel displays the point estimates for quintile dummies of the within-grade ability distribution, with the lowest quintile as the base category. 
in smaller schools. The larger effects in larger schools is evidence against measurement error in the rank variable, which could be due to stratified random sampling. Because a fixed number of students was sampled from a grade regardless of the grade size, we would expect a greater measurement error and, consequently, a greater attenuation bias in larger schools.

We also test whether the effects are different in high- and low-ability schools, as well as in more and less heterogeneous schools. The second row of Figure 2 displays separate effects for schools with an average ability above and below the median: the effect is the same regardless of whether the school has a high or a low average ability. Similarly, we consider schools with a high and low variance in ability. In segregated neighborhoods, we would expect a greater homogeneity within schools, and the ordinal rank could be more important in more or less segregated schools. However, we find no difference in the effect between high- and low-variance schools.

Finally, we consider non-linear effects within a grade. According to the linear effect in Table 3 , going from rank 60 to rank 50 in a cohort of 100 would make the same difference as going from rank 10 to rank 1 . This can hardly be the case. While we lack the statistical power to test for non-linearities along the entire ranking, we provide evidence for a non-linear effect based on quintiles of the within-grade ability distribution. We estimate a model similar to Equation (3) but replace the percentile rank with dummy variables for the quintiles 2-5. The lowest quintile is the base category. As shown in the fourth row of Figure 2, the effect is virtually zero in the bottom half of the within-grade distribution. From the third quintile onwards, the effect is positive, and the relationship between rank and educational outcomes looks linear.

\subsection{Discussion AND ROBUSTNESS CHECKS}

Thus far, we have interpreted the rank effect on educational attainment as causal, given that the individual controls as well as the fixed effects rule out many confounding factors, and based on the assumption that being in one school cohort or another is exogenous to the student. In this section, we discuss various sources of bias and demonstrate that the results are robust to numerous specification checks. Table 4 displays the results. The baseline results in row 1) serve as a benchmark.

Does THE RANK MEASURE REFleCt NON-COGNITIVE SKILls? One concern with the Peabody test score as a measure for cognitive ability is that it could in part reflect personality traits. Peabody is not a high-stakes test, and students had no particular incentive to achieve a high test score. Therefore, one would expect more conscientious students to put more effort into the test and achieve a higher score. Exploiting information on conscientiousness and neuroticism in the first wave of AddHealth, we carry out two tests to assess whether our rank measure, in part, reflects non-cognitive skills. We first regress the percentile rank on both personality measures, controlling for individual characteristics, as well as school and grade fixed effects. If the rank measure reflected non-cognitive skills, we would expect statistically significant coefficients for both non-cognitive skills. As shown in Appendix B, the coefficients are close to zero and statistically insignificant. In Row 2) of Table 4, we also include both measures as endogenous 
Table 4: Robustness checks

\begin{tabular}{lccc}
\hline \hline & \multicolumn{3}{c}{ Dependent variable } \\
\cline { 2 - 4 } Regressor: percentile rank within school cohort & Completed & Attended & Completed \\
high school & college & 4-year degree \\
1) Baseline estimates & & & \\
2) Control for conscientiousness and neuroticism & 0.034 & $0.103^{* * *}$ & $0.101^{* *}$ \\
3) Keep if age $=0.4 \pm$ mean age & $(0.025)$ & $(0.038)$ & $(0.040)$ \\
4) Control for average cohort ability & $(0.025)$ & $(0.038)$ & $(0.040)$ \\
5) Keep grades with female share 40-60\% & 0.006 & $0.088^{*}$ & $0.115^{* *}$ \\
6) Control for gpa & $(0.026)$ & $(0.051)$ & $(0.054)$ \\
7) Relative rank within gender group & $0.054^{*}$ & $0.126^{* * *}$ & $0.081^{*}$ \\
& $(0.030)$ & $(0.045)$ & $(0.047)$ \\
& $0.047^{*}$ & $0.129^{* * *}$ & $0.130^{* * *}$ \\
& $(0.027)$ & $(0.049)$ & $(0.048)$ \\
4lternative regressors & 0.022 & $0.075^{* *}$ & $0.066^{*}$ \\
6) Relative rank within gender group & $(0.024)$ & $(0.037)$ & $(0.038)$ \\
7) Rank among those who completed high-school & 0.029 & $0.119^{* * *}$ & $0.080^{* * *}$ \\
& $(0.019)$ & $(0.031)$ & $(0.031)$ \\
\hline
\end{tabular}

Note: This table displays estimation results for Equation (3). All regressions include individual controls, school fixed effects, and grade fixed effects. In rows 1)-6), the regressor of interest is the percentile rank within a school cohort. In rows 7) and 8), the regressor of interest is the percentile rank within same-gender members of the same cohort (row 7), and the percentile rank among all students who eventualy finished high school (row 8 ). Standard errors, clustered at the school-grade level, are displayed in parentheses, with significance levels $* \mathrm{p}<0.10, * *$ $\mathrm{p}<0.05,{ }^{* * *} \mathrm{p}<0.01$.

controls into the regression and find no significant difference in the estimates compared to the baseline specification.

Are the Results affected by Strategic Delay of SChool entry? The central identifying assumption is that being in a school cohort is as good as random. This assumption holds if the year of school entry is determined by a student's birthday. However, as shown by Deming \& Dynarski (2008), academic redshirting - delaying school entry to allow their children to mature for another year-is widespread in the US. Similarly, students could voluntarily repeat a grade, in which case they would be older than most of their cohort. To test whether the results are affected by these age differences, we restrict the sample to students whose birth date is close enough to the cohort average that we can plausibly exclude redshirting or grade repetition. In Column 3) of Table 4, we restrict the sample to age bands of 0.4 years around the mean age of an entire cohort. The results show that strategic delay is not a threat to our identification. 
The effect on high school completion is now zero, but the effects on college attendance and completion are close to the baseline estimates.

Are the baseline Results affected by AVerage Peer quality? Much of the peer effects literature shows that the average peer ability has a positive impact on individual student outcomes (Sacerdote, 2011). In our baseline model, average peer ability - and in fact any other school-grade-specific characteristic - would be an omitted variable, and bias the estimate of $\gamma$. By using a more demanding specification with school $\times$ grade fixed effects, we were able to net out all confounders at the grade-level within a school, and we have shown in Column 6) of Table 3 that this approach yields very similar results. However, including school $\times$ grade fixed effects takes out a great deal of variation, and identifies the effect only from the differences in the ability variance across cohorts within a school. In Table 4 Row 4), we present the results of a more straightforward specification, in which we include average peer ability as an additional control in the baseline model. The results are similar to those from a model with school $\times$ grade fixed effects as well as the baseline model. The estimate for college attendance is higher than in the other models, but the difference in coefficients is not statistically significant.

Are same-Gender PeErs more important? We were also interested whether all students in the same grade are the relevant comparison group or whether students with the same gender are more important. It may matter more if a girl is the best among all girls, rather than being the best among everyone in the grade. In Row 7) of Table 4, we replace the ordinal rank in a school grade with the ordinal rank within a gender group within a grade. The results are almost identical as in the baseline specification, indicating that same-gender peers are as important as all students in the same cohort.

MEASUREMENT ERROR A potential source of bias is measurement error in the ordinal rank. One source of measurement error could be the over-sampling of minorities. If minority students have a lower average ability compared to white Americans in their grade, and if they are oversampled, then white Americans would be assigned a higher ordinal rank than under random sampling. The sequencing of the sampling in AddHealth offers an opportunity to assess the size of the measurement error. First, a random sample was drawn and labeled as the core sample, and second, additional students were drawn from given minorities. Hence, we observe for each student in the sample the rank with and without over-sampling. The correlation in the percentile ranks in both samples is 0.9867 , indicating that measurement error from over-sampling is not a concern.

A further source of measurement error is gender stratification. Within each school grade, equal numbers of boys and girls were drawn, unless the school is a single-sex school. This sampling could introduce measurement error in the rank measure if the population gender distribution within a grade is skewed. Consider a grade of 100 students, of which 20 are female. If we draw 17 male and 17 female students, then we would sample $85 \%$ of all females, but only $21 \%$ 
of all males in a grade. To assess the extent to which stratified sampling affects the estimates, we exclude grades in which the share of girls is greater than 60

Finally, measurement error could arise from the random sampling of students within grades. In most schools, around $25 \%$ of all students in a school grade were drawn at random. The random sampling introduces a standard measurement error, which may lead to a downward bias in the results. The heterogeneous effects in Figure 2 give us some idea about the magnitude of this bias. Given that the same number of students is drawn regardless of the grade size, we would expect a larger measurement error and smaller estimates in larger schools. While this is not a definitive proof, the evidence goes against a large measurement error, given that we find smaller effects in smaller schools.

SElective ATtRition An additional source of bias is selective attrition. We are not able to track all students from wave I to wave IV; around $25 \%$ of all students attrit from the sample. This attrition may lead to biased estimates if it is correlated with the rank. We address this concern in a robustness check in Appendix B, in which we estimate Equation 3 with the attrition status as the dependent variable, and find no evidence for a systematic relationship between rank and attrition.

An additional source of attrition may have occurred before and up to wave I: high-school dropouts. Because we observe each cohort in a different grade, high-school dropouts should induce a greater attrition in older compared to younger cohorts. To the extent that dropouts predominantly come from the low end of the within-cohort ability distribution, the ability distribution may shift to the right over time. These shifts should not affect our results, because the average shifts would be absorbed by the grade fixed effects, and school-cohort-specific shifts would be absorbed by the school-specific grade fixed effects. Nevertheless, we carry out a robustness check that demonstrates that this dynamic attrition is not an issue. We recalculate the rank measure using only students in wave I who have indicated in wave IV that they completed high school. The results, displayed in row 8) for the two college outcomes, are stable to the use of this alternative rank measure.

Ability vs. GPA We chose cognitive ability, measured by a standardized ability test, as a base for the rank measure mainly because a standardized test allows us to compare students across cohorts within a school. A further possibility would be to rank students according to their grade point average (GPA), which is a more salient measure. At the same time, GPA is not standardized, and thus not comparable across cohorts; it is self-reported, and has a great deal of missing information. One might be concerned, however, that the ability rank is merely a proxy for a rank based on academic performance. In Row 6) of of Table 4, we assess the importance of GPA in explaining the results, by including it as an additional endogenous regressor. If the ability rank was merely reflecting GPA, then its coefficient should be small and statistically insignificant. As shown in Row 6) of of Table 4, including GPA reduces the coefficients by around one third, but they remain statistically and economically significant. Rather than being 
a competing measure for ability, grades can be seen as one channel through which a student's relative ability affects outcomes.

\subsection{Potential Channels}

Table 5: Regression results: rank position and intermediate outcomes, wave I

\begin{tabular}{|c|c|c|}
\hline Dependent Variable & Coefficient & SE \\
\hline \multicolumn{3}{|l|}{ Self-concept } \\
\hline $\mathbf{1}(\mathrm{I}$ am more intelligent than the average) & $0.090^{*}$ & $(0.046)$ \\
\hline \multicolumn{3}{|l|}{ Expectations } \\
\hline $\mathbf{1}$ (I want to go to college) & 0.028 & $(0.040)$ \\
\hline $\mathbf{1}$ (I will likely go to college) & $0.082^{*}$ & $(0.042)$ \\
\hline $\mathbf{1}$ (I will have a college degree by the age of 30 ) & $0.106^{* *}$ & $(0.043)$ \\
\hline \multicolumn{3}{|l|}{ Intrinsic factors } \\
\hline $\mathbf{1}$ (I was often hopeful last week) & $0.110^{* * *}$ & $(0.042)$ \\
\hline $\mathbf{1}$ (I was often happy last week) & -0.002 & $(0.040)$ \\
\hline $\mathbf{1}$ (I was often depressed last week) & 0.029 & $(0.029)$ \\
\hline $\mathbf{1}(\mathrm{I}$ was often fearful last week) & 0.022 & $(0.018)$ \\
\hline \multicolumn{3}{|l|}{ Effort } \\
\hline $\mathbf{1}$ (I was absent at school without excuse) & $-0.115^{* * *}$ & $(0.043)$ \\
\hline \multicolumn{3}{|l|}{ Support from others } \\
\hline $\mathbf{1}(\mathrm{I}$ feel that teachers care about me $)$ & $0.085^{*}$ & $(0.049)$ \\
\hline $\mathbf{1}($ I feel that parents care about me) & 0.003 & $(0.031)$ \\
\hline $\mathbf{1}(\mathrm{I}$ feel that friends care about me) & -0.003 & $(0.017)$ \\
\hline
\end{tabular}

Note: This table displays the results for separate OLS regressions of the outcomes listed in the first column on relative ability rank within a school grade. Each outcome is a dummy variable with value 1 if an event occurred often or was very likely, and zero otherwise. All regressions include school fixed effects, grade fixed effects, and controls for individual ability, age, minority dummies, and parental characteristics. Standard errors, clustered at the school-grade level, are displayed in parentheses, with significance levels ${ }^{*} \mathrm{p}<0.10, * * \mathrm{p}<0.05,{ }^{* * *} \mathrm{p}<0.01$.

The baseline results show a significant effect of ordinal rank in high school on human capital investment later in life. The question remains which mechanisms can explain this reducedform relationship. Here we present theoretical arguments for four mechanisms, and use the rich survey information provided in AddHealth to analyze which of these mechanisms dominates. We run two sets of regressions. First, we explore to what extent rank affects a number of mediating variables. We re-estimate the model in Equation (3) using as the dependent variable a dummy that equals one if the student strongly agrees to a given statement, and zero otherwise. The results of this exercise are displayed in Table 5. Second, we analyze the strength of these variables in explaining the impact of rank on later outcomes by including the mediating variables as endogenous regressors in the baseline model. If a channel matters for the causal pathway from rank to later outcomes, the coefficient for the percentile rank should be smaller once a proxy for 
Table 6: Regressions with mediators as endogenous controls

\begin{tabular}{lccc}
\hline \hline & \multicolumn{3}{c}{ Dependent variable } \\
\cline { 2 - 4 } & $\begin{array}{c}\text { Completed } \\
\text { high school }\end{array}$ & $\begin{array}{c}\text { Attended } \\
\text { college }\end{array}$ & $\begin{array}{c}\text { Completed } \\
\text { 4-year degree }\end{array}$ \\
\hline Baseline estimates & & & \\
& 0.034 & $0.103^{* * *}$ & $0.101^{* *}$ \\
& $(0.025)$ & $(0.038)$ & $(0.040)$ \\
Including endogenous controls: & & & \\
With self-concept & & & \\
& 0.031 & $0.091^{* *}$ & $0.089^{* *}$ \\
With expectations & $(0.025)$ & $(0.038)$ & $(0.039)$ \\
With intrinsic factors and effort & 0.030 & $0.084^{* *}$ & $0.082^{* *}$ \\
& $(0.025)$ & $(0.037)$ & $(0.038)$ \\
With support from parents, teachers, friends & 0.025 & $0.079^{* *}$ & $0.083^{* *}$ \\
& $(0.025)$ & $(0.038)$ & $(0.040)$ \\
With all variables & 0.031 & $0.095^{* *}$ & $0.094^{* *}$ \\
& $(0.025)$ & $(0.038)$ & $(0.039)$ \\
& 0.015 & 0.053 & 0.048 \\
& $(0.024)$ & $(0.036)$ & $(0.037)$ \\
\hline
\end{tabular}

Note: The results in this table show by how much the point estimates of the percentile rank are attenuated when mediating variables are included. The table displays OLS estimates for the baseline model in Equation 3, including the variables outlined in Table 5 as additional regressors. Standard errors, clustered at the school-grade level, are displayed in parentheses, with significance levels ${ }^{*} \mathrm{p}<0.10,{ }^{* *} \mathrm{p}<0.05,{ }^{* * *} \mathrm{p}<0.01$.

the channel is included.

The first three channels affect the demand for schooling. In a basic human capital model, a student chooses her level of schooling optimally by equating the marginal costs of one more year of schooling with the marginal gains. In such a model, the ordinal rank can affect the marginal costs of investing in education in various ways. The fourth channel works through the supply side. Colleges may place restrictions on the number of slots available, which can be one explanation of the effects.

\subsubsection{RANK PROVIDES INCOMPLETE INFORMATION OF ONE'S OWN ABILITY}

One mechanism could be that the rank provides students with incomplete information about their own ability. There is ample evidence that students have imperfect knowledge about their actual ability (Jensen, 2010; Zafar, 2011; Stinebrickner \& Stinebrickner, 2012; Bobba \& Frisancho, 2014). The ordinal rank can be one reason for this imperfect knowledge. Students may infer their absolute ability from their relative ability within their cohort, and this misinterpretation may affect their education choices later in life. A low rank may lead a student to believe that she has low gains from education, and she may choose not to go to college, even if she is brighter than most students of her age cohort. ${ }^{8}$

\footnotetext{
8 This would mainly work through the marginal costs of schooling. A low perceived ability leads to a higher
} marginal costs, in which case students optimally choose less education. 
Here we provide evidence that the ordinal rank affects perceived ability and expectations. We first assess whether students with a higher rank have a higher perceived ability - a frequent finding in the psychology literature (Marsh, 1987). As shown in the first panel of Table 5, this is indeed the case. In wave I of AddHealth, students were asked if they think that they are more intelligent than the average. Conditional on absolute ability, students with a 10 percentage points higher rank are 0.9 percentage points more likely to believe that they are more intelligent than the average. Table 5 shows that self-concept can explain part of the overall effect of rank on later outcomes. The coefficients for the college variables are around 10 percent lower once perceived ability is included.

Furthermore, we proxy for expected returns to education with various measures of career expectations. In wave I, students were asked whether they want to go to college, whether they will likely go to college, and whether they expect to have a college degree at the age of 30 . We find strong support that rank affects expected returns to education. As shown in the second panel of Table 5, students with a higher rank are more likely to state that they will go to college, and they are more likely to think that they will have a college degree by age 30. Remarkably, the impact of rank on college expectations at age 16 is equally as large as the impact of rank on actual college outcomes more than 10 years later. Also, as shown in Table 6, including expectations attenuates the baseline estimate by around 20\%, showing that the expectations channel is quantitatively important.

INTRINSIC FACTORS AND EFFORT The effect could also be explained by intrinsic factors. As suggested by the literature on relative comparisons and effort provision, a higher rank may give students a greater motivation, make them more self-confident, and ultimately induce them to exert more effort in their studies (Clark et al., 2010; Azmat \& Iriberri, 2010). Effort, in turn, would increase the marginal gains from schooling, and induce students to choose more schooling.

The third panel in Table 5 displays the impact of ordinal rank on intrinsic factors, exploiting questions from a survey module on mental distress. Students with a higher rank are significantly more optimistic, while we find no effect of rank on happiness, depression, or fearfulness. To proxy for effort, we use self-reported information on school absences, and construct a dummy that equals one if the student has been absent without excuse at least once in the previous school year. We find that students with a higher rank are significantly less likely to be absent without excuse, which indicates that they take their studies more seriously and put more effort into it. In Table 6 we include the intrinsic factors and the absence dummy into the baseline regression. These factors explain as much of the effect of rank on educational attainment as the inclusion of expectations. The coefficients are around $20 \%$ smaller.

BeHAVIORAL RESPONSES FROM TEACHERs, PARENTS, AND FRIENDS A further potential channel is behavioral responses from a student's environment. As shown by Pop-Eleches \& Urquiola (2013), teachers and parents are responsive to a student's relative position within their school. They compare marginal students who just made it into a high-quality school to those 
who did not and find that parents provide less effort when their child attends a better school. Moreover, teachers could have a preference for students with a higher rank and give them more support. More support from the environment lowers the marginal costs of schooling, and-all else equal — should lead to more schooling.

In the fifth panel of Table 5, we show the effect of percentile rank on perceived support from teachers, parents, and friends. Students were asked whether they believe that these groups care about them. The ordinal rank has indeed a positive impact on the perceived support from teachers. Students with a higher rank are more likely to feel that their teachers care about them. The effects on the perceived support from parents and friends, in contrast, are small and statistically insignificant. When we include the support variables into the main regression, the coefficient of the percentile rank does not decrease by a large amount, indicating that the support from the environment plays a minor role in explaining the result.

Selective COLlege ADMissions Finally, the effect can be explained by college admissions. Colleges may have a fixed number of slots and/or a fixed amount of financial aid available and may give priority to students with a higher within-school rank. In light of the channels we analyzed so far, college admissions, if anything, can only explain part of the effect. We have shown that rank affects a student's perceived ability, ambition, effort, and expectations before students apply for colleges. If supply side restrictions were the only explanations for the effect, then we should not see a significant effect of rank on these other outcomes. Moreover, the outcome variable attended college includes all colleges in the US, that is, it also includes a vast number of non-selective community colleges for which these restrictions typically do not apply. If restrictions were the only explanation, we would expect to find no effect on attending any college.

A further supply-side channel is affirmative action, through which colleges may give preferential access to students from minorities or from schools in disadvantaged areas. While affirmative action has been shown to significantly distort sorting into colleges (Arcidiacono, 2005), it should not explain our results, because we control for many characteristics that define the minorities targeted by affirmative action, such as Blacks or Hispanics. However, following prominent lawsuits in the mid-1990s, many state colleges in the US have abandoned affirmative action. Instead, California, Texas, and Florida introduced ten-percent plans, granting students in the top 10 percent of their high school cohort automatic access to flagship state universities. ${ }^{9}$ These $10 \%$-plans were introduced three years after the first wave of AddHealth was collected and, thus, should only affect the youngest cohorts, if at all.

Besides these plans that specifically apply to students with a given rank, the effect of rank on college outcomes can more generally be explained by selective college admission policies. Stu-

\footnotetext{
$9 \quad$ Daugherty et al. (2014) for Texas and Arcidiacono et al. (2014) for California give evidence that the introduction of these plans changed the composition of students at flagship state colleges. In Texas, attendance and completion rates at these colleges increased, but more so for students from high-ability high schools. In California the college attendance rates of Blacks increased, but larger shares of Blacks went to lower-ranked colleges.
} 
dents typically apply for college with their 11th-grade results, which often state the percentile of a student in the GPA distribution of her grade. If college admission officers have this information, and if GPA rank is positively correlated with the ability rank, then our result could reflect a pure mechanical effect: colleges only admit students with a higher rank, which is why we observe higher college attendance rates for highly ranked students. While we do not have direct information on the type of college to which students apply or are admitted, we have shown in Table 4 that GPA can only explain a small fraction of the effect of rank on college attendance. Hence, college admissions can -if at all —only in part explain the results.

\section{Conclusion}

In this paper we show that a student's ordinal rank in a high school cohort is an important determinant for educational attainment later in life. Comparing students across cohorts within the same school, and flexibly controlling for cognitive ability, we find that students with a higher ordinal rank in their cohort are more likely to complete high school, attend college, and complete a 4-year degree. This effect runs counter to most of the literature on peer effects, which finds that being exposed to better peers has a positive effect on educational attainment.

Exploiting rich survey information, we provide evidence on the mechanisms that help to explain this result. We find that students with a higher rank have higher expectations about their future career outcomes, they are more optimistic and more self-confident, and they receive more attention from their teachers. These results suggest that students base their schooling decisions in part on their relative rather than their absolute ability. The ordinal rank provides students with noisy information about their own ability, which in turn distorts the trade-off between the short-run costs and the long-run benefits from schooling.

Our results should concern parents and policymakers alike. A student's relative position in a cohort affects outcomes later in life, and parents should take the rank of their child into account when choosing the right school for their child. The highest-ranked school may not be beneficial for children at the margin who only just make it into the school. However, it is also important to note that rank is only one aspect of school choice. Our results reflect local effects, which we obtained by comparing students within the same school but in different cohorts. If parents chose schools exclusively based on their child's rank, they would ignore many other school inputs that are equally important, such as teacher quality, average peer ability, and school resources.

Policymakers should be concerned, because our results show that students with a high ability but a low rank - small fish in a big pond - under-invest in their human capital. Students seemingly place too much weight on their relative ability and too little on their absolute ability when making college decisions. It is difficult to think of an algorithm that reduces this inefficiency by regrouping students into schools, because the ordinal rank is a relative measure, and improving one student's rank means worsening the rank of another. A more efficient policy could be to give more support to students at lower ranks of the ability distribution in order to compensate for the negative impact of their rank. Especially for students with a low rank in high-ability 
schools, providing them with information on their absolute ability could be an inexpensive and effective way to increase their educational attainment. Recent experimental studies by Azmat \& Iriberri (2010), Tran \& Zeckhauser (2012), Hastings \& Weinstein (2008), Bettinger et al. (2012), Oreopoulos \& Dunn (2013) and Wiswall \& Zafar (2015) have shown that students are indeed responsive to these type of interventions. 


\section{REFERENCES}

Abdulkadiroglu, Atila, Angrist, Joshua D., \& Pathak, Parag A. 2014. The Elite Illusion: Achievement Effects at Boston and New York Exam Schools. Econometrica, 82(1), $137-196$.

Ammermueller, Andreas, \& Pischke, Jörn-Steffen. 2009. Peer Effects in European Primary Schools: Evidence from the Progress in International Reading Literacy Study. Journal of Labor Economics, 27(3), 315-348.

Arcidiacono, Peter. 2005. Affirmative Action in Higher Education: How do Admission and Financial Aid Rules Affect Future Earnings? Econometrica, 73(5), 1477-1524.

Arcidiacono, Peter, Aucejo, Esteban, Coate, Patrick, \& Hotz, V. Joseph. 2014. Affirmative Action and University Fit: Evidence from Proposition 209. IZA Journal of Labor Economics, 3:7.

Attanasio, Orazio P., \& Kaufmann, Katja M. 2015. Education Choices and Returns to Schooling: Mothers' and Youths' Subjective Expectations and their Role by Gender. Journal of Development Economics, 109C, 203-216.

Azmat, Ghazala, \& Iriberri, Nagore. 2010. The Importance of Relative Performance Feedback Information: Evidence from a Natural Experiment using High School Students. Journal of Public Economics, 94, 435-452.

Bettinger, Eric P., Long, Bridget Terry, Oreopoulos, Philip, \& Sanbonmatsu, LisA. 2012. The Role of Application Assistance and Information in College Decisions: Results from the H\&R Block FAFSA Experiment. The Quarterly Journal of Economics, 127(3), $1205-242$.

Bifulco, Robert, Fletcher, Jason M., \& Ross, Stephen L. 2011. The Effect of Classmate Characteristics on Post-Secondary Outcomes: Evidence from the Add Health. American Economic Journal: Economic Policy, 3, 25-53.

Bobba, Matteo, \& Frisancho, Veronica. 2014. Learning About Oneself: The Effects of Signaling Academic Ability on School Choice. Inter-American Development Bank, mimeo.

Booij, Adam, Leuven, Edwin, \& Oosterbeek, Hessel. 2015. Ability Peer Effects in University: Evidence from a Randomized Experiment. IZA Discussion Paper, 8769.

Burke, Mary A., \& Sass, Tim A. 2013. Classroom Peer Effects and Student Achievement. Journal of Labor Economics, 31(1), 51-82.

Calvó-Armengol, Antoni, Patacchini, Eleonora, \& Zenou, Yves. 2009. Peer Effects and Social Networks in Education. Review of Economic Studies, 76, 1239-1267. 
Carrell, Scott E., Fullerton, Richard L., \& West, James E. 2009. Does Your Cohort Matter? Measuring Peer Effects in College Achievement. Journal of Labor Economics, 27(3), 429-464.

Carrell, Scott E., Sacerdote, Bruce I., \& West, James E. 2013. From Natural Variation to Optimal Policy? The Importance of Endogenous Peer Group Formation. Econometrica, 81(3), 855-882.

Clark, Andrew, Masclet, David, \& Villeval, Marie-Claire. 2010. Effort and Comparison Income: Experimental and Survey Evidence. Industrial and Labor Relations Review, 63(3), 407-426.

Cullen, Julie Berry, Long, Mark C., \& Reback, Randall. 2013. Jockeying for Position: Strategic High School Choice under Texas' Top Ten Percent Plan. Journal of Public Economics, 97, 32-48.

Daugherty, Lindsay, Martorell, Paco, \& McFarlin Jr, Isaac. 2014. Percent Plans, Automatic Admissions, and College Outcomes. IZA Journal of Labor Economics, 3:10.

De Giorgi, Giacomo, \& Pellizzari, Michele. 2014. Understanding Social Interactions: Evidence from the Classroom. Economic Journal, 124(579), 917-953.

Deming, David, \& Dynarski, Susan. 2008. The Lengthening of Childhood. Journal of Economic Perspectives, 22(3), 71-92.

Dunn, Lloyd M., \& Dunn, Leota M. 2007. The Peabody Picture Vocabulary Test. 4th edn. Bloomington, MN: NCS Pearson, Inc.

Feld, JAn, \& Zölitz, Ulf. 2014. On the Nature, Estimation and Channels of Peer Effects. University of Gothenburg Working Papers in Economics, 596.

Hanushek, Eric A., Kain, John F., Markman, Jacob M., \& Rivkin, Steven G. 2003. Does Peer Ability Affect Student Achievement? Journal of Applied Econometrics, 527-544.

Harris, Kathleen Mullan. 2009. The National Longitudinal Study of Adolescent to Adult Health. doi: 10.3886/ICPSR27021.v9.

Harris, K.M., Halpern, C.T., Whitsel, E., Hussey, J., Tabor, J., Entzel, P., \& UDRY, J.R. 2009. The National Longitudinal Study of Adolescent to Adult Health: Research Design [WWW document]. URL: http://www.cpc.unc.edu/projects/addhealth/design.

Hastings, Justine S., \& Weinstein, Jeffrey M. 2008. Information, School Choice, and Academic Achievement: Evidence from Two Experiments. The Quarterly Journal of Economics, 123, 1373-1414.

Hoxby, Caroline. 2000a. The Effects of Class Size on Student Achievement: New Evidence from Population Variation. The Quarterly Journal of Economics, 115(4), 1239-1285. 
Hoxby, Caroline. 2000b. Peer Effects in the Classroom: Learning from Gender and Race Variation. NBER Working Paper, 7867.

Imberman, Scott, Kugler, Adriana D., \& Sacerdote, Bruce. 2012. Katrina's Children: Evidence on the Structure of Peer Effects from Hurricane Evacuees. American Economic Review, 102(5), 2048-2082.

Jensen, Robert. 2010. The Perceived Returns to Education and the Demand for Schooling. The Quarterly Journal of Economics, 125(2), 515-548.

Koppensteiner, Martin Foureaux. 2012. Class Assignment and Peer Group Effects: Evidence from Brazilian Primary Schools. University of Leicester Working Paper, 03.

Lavy, Victor, Silva, Olmo, \& Weinhardt, Felix. 2012. The Good, the Bad and the Average: Evidence on Ability Peer Effects in Schools. Journal of Labor Economics, 30(2), $367-414$.

Marsh, Herbert W. 1987. The big-fish-little-pond effect on academic self-concept. Journal of Educational Psychology, 79(3), 280.

Marsh, Herbert W., Trautwein, Ulrich, Lüdtke, Oliver, Baumert, Jürgen, \& Köller, Olaf. 2007. The Big-Fish-Little-Pond Effect: Persistent Negative Effects of Selective High Schools on Self-Concept After Graduation. American Educational Research Journal.

Murphy, Richard, \& Weinhardt, Felix. 2014. Top of the Class: The Importance of Ordinal Rank. CESifo Working Paper, 4815.

Oreopoulos, Philip, \& Dunn, Ryan. 2013. Information and College Access: Evidence from a Randomized Field Experiment. Scandinavian Journal of Economics, 115(1), 3-26.

Patacchini, Eleonora, Rainone, Eduardo, \& Zenou, Yves. 2012. Student Networks and Long-Run Educational Outcomes: The Strength of Strong Ties. CEPR Discussion Paper, 9149.

Pop-Eleches, Cristian, \& Urquiola, Miguel. 2013. Going to a Better School: Effects and Behavioral Responses. American Economic Review, 103(4), 1289-1324.

Sacerdote, Bruce. 2001. Peer Effects with Random Assignment: Results for Dartmouth Roommates. The Quarterly Journal of Economics, 116(2), 681-704.

Sacerdote, Bruce. 2011. Peer Effects in Education: How Might They Work, How Big Are They, and how much Do We Know thus far? In: Hanushek, Eric A., Machin, Stephen, \& Woessmann, Ludger (eds), Handbook of the Economics of Education, vol. 3. NorthHolland.

Stinebrickner, Todd, \& Stinebrickner, Ralph. 2012. Learning about Academic Ability and the College Drop-out Decision. Journal of Labor Economics, 30(4), 707-748. 
Stinebrickner, Todd, \& Stinebrickner, Ralph. 2014. A Major in Science? Initial Beliefs and Final Outcomes for College Major and Dropout. Review of Economic Studies, 81(1), $426-472$.

Tatsi, Eirini. 2015. Endogenous Social Interaction: Which Peers Matter? Goethe University Frankfurt, mimeo.

Tincani, Michela. 2015. Heterogeneous Peer Effects and Rank Concerns: Theory and Evidence. University College London, mimeo.

Tran, Anh, \& Zeckhauser, Richard. 2012. Rank as an Inherent Incentive: Evidence from a Field Experiment. Journal of Public Economics, 96, 645-650.

Wiswall, Matthew, \& Zafar, Basit. 2015. Determinants of College Major Choices: Identification from an Information Experiment. Review of Economic Studies, 82(2), 791-824.

Zafar, BAsit. 2011. How do College Students Form Expectations? Journal of Labor Economics, 29(2), 301-348.

Zimmerman, David J. 2003. Peer Effects in Academic Outcomes: Evidence from a Natural Experiment. Review of Economics \& Statistics, 85(1), 9-32. 


\section{A Disclaimer}

This research uses data from Add Health, a program project directed by Kathleen Mullan Harris and designed by J. Richard Udry, Peter S. Bearman, and Kathleen Mullan Harris at the University of North Carolina at Chapel Hill, and funded by grant P01-HD31921 from the Eunice Kennedy Shriver National Institute of Child Health and Human Development, with cooperative funding from 23 other federal agencies and foundations. Special acknowledgment is due Ronald R. Rindfuss and Barbara Entwisle for assistance in the original design. Information on how to obtain the Add Health data files is available on the Add Health website (http://www.cpc.unc.edu/addhealth). No direct support was received from grant P01-HD31921 for this analysis.

\section{B Robustness CHECKS}

Table 7: Robustness checks

\begin{tabular}{lcc}
\hline \hline & \multicolumn{2}{c}{ Dependent variable } \\
\cline { 2 - 3 } Neuroticism & Percentile rank & Attrition dummy \\
& -0.001 & \\
Conscientiousness & $(0.001)$ & \\
Relative rank & 0.001 & \\
& $(0.001)$ & -0.010 \\
& & $(0.036)$ \\
\hline
\end{tabular}

Note: This table presents additional robustness checks. In the left column, the rank is regressed on non-cognitive skills, individual controls, ability, school and grade fixed effects. In the column on the right an attrition dummy is regressed on the ordinal rank, individual controls, ability, and school and grade fixed effects. Standard errors, clustered at the school-grade level, are displayed in parentheses, with significance levels $* \mathrm{p}<0.10,{ }^{* *} \mathrm{p}<0.05,{ }^{* * *}$ $\mathrm{p}<0.01$.

In this section, we present further robustness checks. The first check addresses the concern that the Peabody score is partly driven by non-cognitive skills, which would be an omitted variable in the regression. The second check provides evidence against selective attrition.

Peabody test scores AND Non-Cognitive skills One concern with using the Peabody test scores as ability measures is that Peabody is a low-stakes test in which students have little incentive to do well. In light of this, more conscientious students may perform better on the test simply because they take the test more seriously. In Row 2), we include measures for conscientiousness and neutoticism, measured in wave I, as additional regressors. If they were significant confounders, their inclusion should fundamentally change the results. As can be seen in Row $2)$, this is not the case. 
Selective Attrition In Section 4.3, we explained that the results could be biased due to selective attrition, for example if we are less likely to observe lower-ranked students in wave IV. To assess the importance of selective attrition, we re-estimate the baseline model on the full sample of wave I, and use as outcome variable an attrition dummy that equals one if the person is not in the sample in wave IV. As shown in Panel B of Table 7, selective attrition is unrelated to rank and should not lead to a systematic bias in our estimates. 